Article

\title{
The Influence of Neodymium Element on the Crater Structure Formed on A1-17.5Si Alloy Surface Processed by High-Current Pulsed Electron Beam
}

\author{
$\mathrm{Kui} \mathrm{Li}^{1}{ }^{1}$, Bo Gao ${ }^{1, * \mathbb{D}}$, Ning Xu ${ }^{1}$, Yue Sun ${ }^{1}$, Vladimir Viktorovich Denisov ${ }^{2}$ and Liang Hu ${ }^{1}$ \\ 1 Key Laboratory for Ecological Metallurgy of Multimetallic Mineral (Ministry of Education), \\ Northeastern University, Shenyang 110819, Liaoning, China; 1871289@stu.neu.edu.cn (K.L.); \\ xun0909@126.com (N.X.); 1971408@stu.neu.edu.cn (Y.S.); surflik@163.com (L.H.) \\ 2 Institute of High Current Electronics, Siberian Branch, Russian Academy of Sciences, 634055 Tomsk, Russia; \\ volodyadenisov@yandex.ru \\ * Correspondence: gaob@smm.neu.edu.cn; Tel.: +86-24-83681320
}

Received: 26 August 2020; Accepted: 21 September 2020; Published: 25 September 2020

\begin{abstract}
The effect of neodymium element on the elimination of crater structures on the surface of Al-17.5Si metallic materials processed by high-current pulsed electron beam was investigated in this study. Field emission scanning electron microscopy analysis indicated that the grain sizes of Al-17.5Si metallic materials were reduced and craters were removed from surfaces of the processed Al-17.5Si metallic material after addition of $\mathrm{Nd}$. This can be attributed to the efficient transfer of heat accumulated in rich-silicon (primary silicon) areas without the eruption of a primary silicon phase if the size of primary silicon grains are small. The $\mathrm{X}$-ray diffraction analysis indicates that all diffraction peaks are broadened because of the presence of structural defects, grain refinement and stress state. Electron probe micro-analyzer analysis demonstrated that $\mathrm{Al}$ and $\mathrm{Nd}$ were evenly distributed on the surface of the treated alloy, which could be attributed to the diffusion of the element. Transmission electron microscopy analysis showed that nano-Al and nano-Si cellular textures were generated during the treated process. The formation of these structures can be attributed to rapid heating and cooling effects by the treatment. Finally, electrochemical tests revealed that the corrosion current density of Al-17.5Si metallic materials (with $\mathrm{Nd}, 0.3 \mathrm{wt} . \%$.) surface decreased by three orders of magnitude compared with that of the processed Al-17.5Si metallic material surfaces (without $\mathrm{Nd}$ ). This can be attributed to the elimination of craters and grain refining.
\end{abstract}

Keywords: nano-silicon; neodymium element; high-current pulsed electron beam; crater structure

\section{Introduction}

Recently, due to its higher specific strength, lighter weight, excellent weld-ability, and high heat resistance, Al-Si alloy has been widely used in manufacturing of parts with complex shapes, thin walls, and high corrosion-resistant parts (e.g., high-speed railway emu pillow beams, engine pistons, turbo pump housing [1,2]. However, the mechanical properties and corrosion resistance of Al-Si alloys are seriously affected because of the existence of coarse irregular primary silicon phase $[3,4]$. As a kind of rapid solidification method, electron beam treatment has become an effective method to improve the properties of Al-Si alloys because of its high efficiency of refining primary silicon phase, and has received an increasing amount of attention.

As an important tool for modification of material surfaces, high-current pulsed electron beam (HCPEB) has seen rapid development in recent years. HCPEB has been widely applied for semiconductor materials, metallic materials and polymers because of its environmentally friendly features, low energy consumption and high efficiency [5-10]. Super-fast heating and cooling processes, 
which can be beneficial to the refinement of a primary silicon phase in Al-Si alloy, are induced by HCPEB treatment, resulting in a specific surface modification effect which is unattainable by traditional surface treatment methods. This effect may change the physical, chemical, and mechanical properties of materials surfaces [11,12].

However, due to defects (e.g., microcracks and crater structures) on the surfaces of HCPEB-processed alloy, further applications of the alloy in industry are limited. For example, the crater structures on alloy top surfaces after HCPEB treatment lead to sharply deteriorated fatigue resistances, wear resistances and corrosion resistances [13-15]. Pogrebnjak et al. [16] observed the formed crater structures on the iron surface treated by a pulsed electron beam for the first time, and found that the structures deteriorated the corrosion resistance of the material. Following studies indicated that it is difficult to avoid the formation of crater structures in the process of pulse electron beam treatment because of the energy deposition of the electron beam [17,18]. Therefore, how to eliminate the crater structures has become a widely studied problem for researchers.

By optimizing the equipment parameters and improving the experimental instruments, the researchers tried to eliminate the defect structure formed during pulsed electron beam treatment, but there are some problems, such as little effect and high price [19,20]. Zhu et al. [21] found that the generation of crater structures on the titanium surfaces induced by an ion beam was closely related to the roughness of the initial sample. Specifically, crater structures tend develop on alloy surfaces with high roughness. Therefore, roughness reduction may reduce the density of crater structures on the alloy surfaces and improve its homogeneity. It provides a feasible method for the elimination of the crater structure.

Previous studies have demonstrated that neodymium element is beneficial to the removal of impurities, casting defects and microcracks, and improves the mechanical properties and corrosion resistance of aluminum alloys [22-24]. However, few studies have discussed the effects of elimination of crater structures by adding neodymium elements on the surfaces of HCPEB-processed alloy. We investigated the effects of elimination of crater structures with $\mathrm{Nd}$ addition on the top layer of Al-17.5Si alloy processed by HCPEB and proposed the corresponding mechanism in this research. Furthermore, electrochemical tests revealed the corrosion resistance of the top layer of the metallic material.

\section{Materials and Methods}

For the study, Al-17.5Si metallic materials without and with added $\mathrm{Nd}(0.3 \mathrm{wt} . \%)$ were investigated. The only difference regarding preparation process of the Al-17.5Si and $\mathrm{Al}-\mathrm{Si}-\mathrm{Nd}$ metallic materials is that $\mathrm{Nd}$ was added in the form of an intermediate alloy (Al-10Nd) at $760^{\circ} \mathrm{C}$ and this temperature was maintain for $8 \mathrm{~min}$ to prepare the Al-Si-17.5Nd alloy. After that, we poured the melted alloy into a 304 stainless steel cylinder that has a diameter of $20 \mathrm{~mm}$ and a height of $150 \mathrm{~mm}$ at $730{ }^{\circ} \mathrm{C}$ to obtain the modified alloy. Prior to the high current pulsed electron beam (HCPEB) treatment, we cut the samples into cylinders that had a diameter of $10 \mathrm{~mm}$ and a height of $10 \mathrm{~mm}$ and polished by sandpaper with different roughness (100\#, 240\#, 400\#, 800\#, 1500\#, 3000\#) and diamond paste of $1 \mu \mathrm{m}$.

The alloy surface was treated by HCPEB (MMLAB-HOPE-I, Dalian, China) and the technological parameters were optimized to obtain melting the treated surface area without significant evaporation. The following were the corresponding parameters of the HCPEB equipment: pulse duration $=3 \mu \mathrm{s}$, number of pulses $=25$, electron expedited voltage $=20 \mathrm{kV}$, average energy density $=2 \mathrm{~J} \cdot \mathrm{cm}^{-2}$, vacuum degree $=6 \times 10^{-3} \mathrm{~Pa}$.

Surface topography of the aluminum silicon metallic material original samples and HCPEB-processed samples were investigated by field emission scanning electron microscopy (FESEM Hitachi S-4800, Tokyo, Japan). Metastable structures were visualized by transmission electron microscopy (TEM, Tecnai G20, Hillsboro, OR, USA). The phase and element compositions of alloy surfaces were analyzed by field emission electron probe micro analyzer (FEEPMA JEOL JXA-8530F, Tokyo, Japan) and X-ray diffraction (XRD-7000, Tokyo, Japan, the wavelength of X-ray anode type 
based on $\mathrm{Cu}=1.5406 \times 10^{-10} \mathrm{~m}$, scanning step $=0.02^{\circ}$, accelerating voltage $=40 \mathrm{kV}$, current $=100 \mathrm{~mA}$, scanned range $(2 \theta)=20^{\circ}-100^{\circ}$, and the scanning speed $=4^{\circ} \mathrm{min}^{-1}$ ). The corrosion resistances of alloy surfaces were measured by an electrochemical workstation (Autolab PGSTAT30, Herisau, Switzerland), the $\mathrm{Pt}$ and saturated calomel electrodes in $3.5 \% \mathrm{NaCl}$ solution were regarded as counter and reference electrodes.

\section{Results and Discussion}

\subsection{Surface Topography of Al-17.5Si Metal Original Samples and HCPEB-Processed Samples}

Figure 1 shows the surface topography of the Al-17.5Si alloy original samples and HCPEB-processed samples. As exhibited in Figure 1a, the Al-17.5Si metallic materials mainly consisted of coarse primary silicon phase (the first precipitated silicon solid solution phase with rarely dissolved aluminum elements during the crystallization process of the Al-Si alloy), acicular eutectic silicon and aluminum matrix, in terms of microstructure. Specifically, the size of the primary silicon phase was 50-200 $\mu \mathrm{m}$, and it split the Al matrix. As shown in Figure 1b, crater structures were generated after HCPEB treatment ( 25 pulses, no Nd). The density of crater structures was about $30.79 \mathrm{~mm}^{-2}$, according to statistical results. The mechanism of crater density development was as follows: upon exposure to HCPEB, the Al-Si alloy surface melted rapidly, which was accompanied by heat transformation, due to the high energy of electron beam. However, heat transfer from the silicon-rich zone (the zone containing a large amount of primary silicon phase) during melting was difficult because of the low conductivity of the brittle primary silicon, leading to high temperature inside the silicon-rich zone, compared with the Al-rich zone. As a result, the eruption was observed and crater structures were generated $[23,25]$.
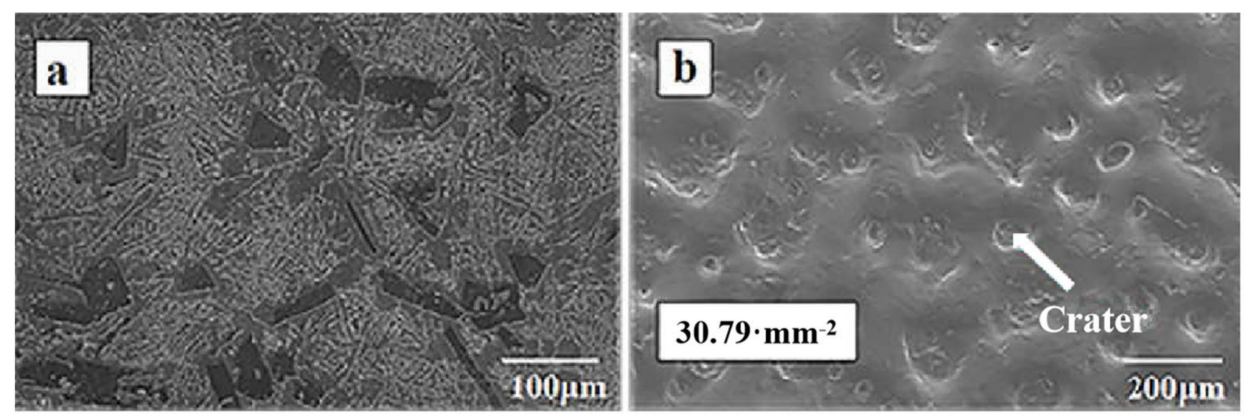

Figure 1. (a) Surface morphologies of Al-17.5Si metallic materials. (b) Surface morphologies of high-current pulsed electron beam (HCPEB)-processed Al-17.5Si metallic materials (25 pulses).

Figure 2 reveals the SEM images of the Al-17.5Si-0.3Nd metallic material original samples and HCPEB-processed samples. As observed, the dimension of the primary silicon phase was significantly reduced after the addition of $\mathrm{Nd}$. This is consistent with previous studies [26-28]. The constitutional super-cooling theory is a reasonable explanation about the refining of primary silicon by rare earth elements. At the beginning of solidification, $\mathrm{Nd}$ was adsorbed and rapidly enriched in front of the primary silicon interface, resulting in inhibited growth of primary silicon phases. Figure $2 \mathrm{~b}$ reveals that few craters were formed on the top layer of Al-17.5Si-0.3Nd metallic materials processed by HCPEB (25 pulses). The density of crater structures was only $1.78 / \mathrm{mm}^{2}$, which was $5.7 \%$ of that of the sample with no $\mathrm{Nd}$ added. This can be attributed to the presence of rare earth elements. The surface of Al-17.5Si-0.3Nd metallic materials melted rapidly upon HCPEB process, during melting, as primary silicon refined by $\mathrm{Nd}$ addition can induce slight heat accumulation only, and the heat in rich silicon can be transferred to Al-rich zone quickly. Hence, eruption can be significantly reduced and craters can be barely generated. Additionally, casting defects, surface roughness and alloy impurities can be reduced by Nd addition $[29,30]$. Eruption tends to appear at casting defects and in impurity 
phases [23], while addition of $\mathrm{Nd}$ can effectively remove casting defects and impurity phases, resulting in uniform tissue and effective removal of craters.
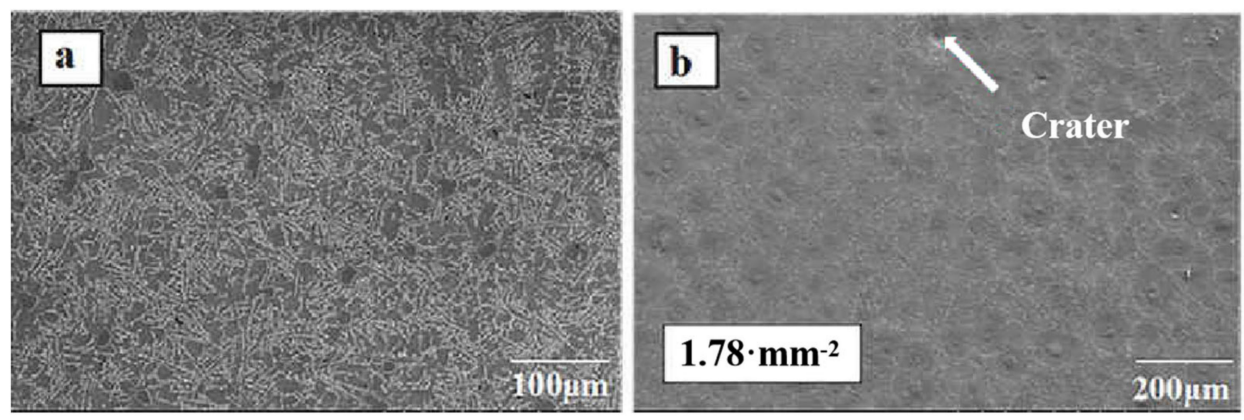

Figure 2. (a) Surface morphologies of Al-17.5Si-0.3Nd metallic materials. (b) Surface morphologies of HCPEB-processed Al-17.5Si-0.3Nd metallic materials (25 pulses).

\subsection{XRD Results of the Al-17.5Si-0.3Nd Metal Original Samples and HCPEB-Processed Samples}

Figure 3 displays the XRD patterns of the Al-17.5Si-0.3Nd metallic materials original samples and HCPEB-treated samples. As shown in Figure 3a, no new diffraction peak was observed after the HCPEB process (25 pulses), indicating that no fresh phase was generated after the HCPEB process. Figure $3 \mathrm{~b}$ gives a partial enlargement of Figure 3a. The peaks of diffraction were significantly broadened and shifted after HCPEB process. The widening of diffraction peaks can be annotated to the presence of structural defects, grain refinement and stress state [29], while the shifts of the diffraction peaks can be attributed to the stress state of the alloy surface [30]. Meanwhile, no Nd-rich phase was generated, according to the XRD diffraction patterns. This can be attributed to the low content of $\mathrm{Nd}$. In this case, most of the $\mathrm{Nd}$ element served as solid solutes in the $\alpha(\mathrm{Al})$ or primary Si phase, resulting in lattice distortion. For this reason, the diffraction peaks were seen to shift towards the high angle direction, as exhibited in Figure 3b.
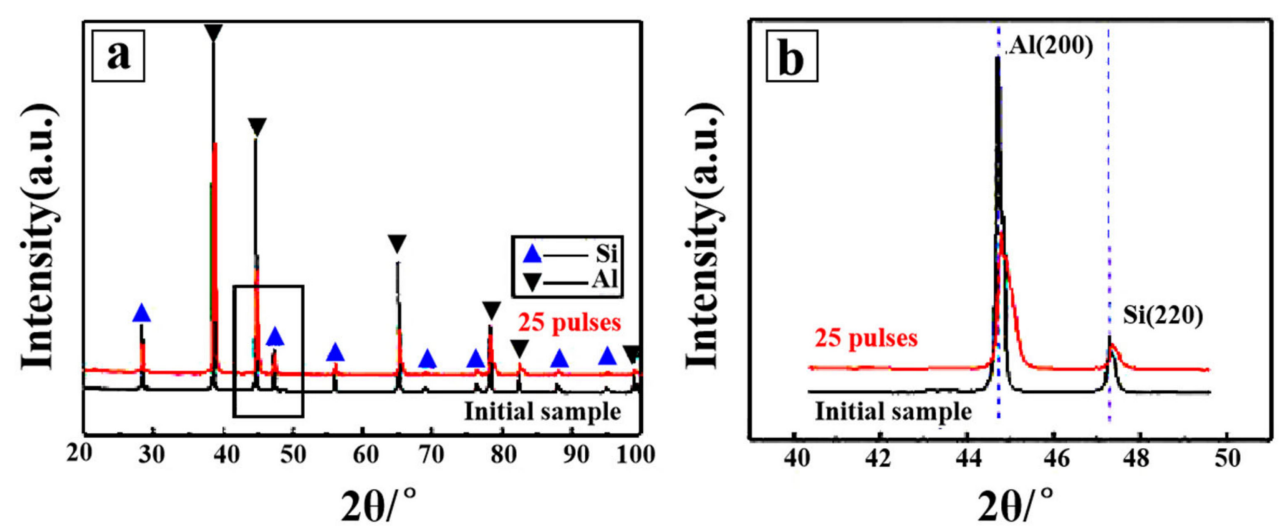

Figure 3. (a) XRD diffraction pattern of Al-17.5Si-0.3Nd alloy surface with and without HCPEB process XRD pattern; (b) partial enlargement of (a).

\subsection{Surface Electron Probe Micro Analyzer (EPMA) Analyses of the HCPEB-Processed Al-17.5Si-0.3Nd Metallic Materials}

Figure 4 shows EPMA element distribution graphics of craters in the top layer of HCPEB-processed $\mathrm{Al}-17.5 \mathrm{Si}-0.3 \mathrm{Nd}$ metallic materials (25 pulses). It can be seen that $\mathrm{Nd}$ and $\mathrm{Al}$ were evenly distributed on the surface of HCPEB-processed alloy: Si was rich in crater bottoms, while few craters were observed, which supported the SEM analysis. Meanwhile, $\mathrm{Al}$ and $\mathrm{Si}$ elements presented gradient distributions in craters due to diffusion of element during HCPEB. Si element diffused from crater center to crate edge, while $\mathrm{Al}$ element spread from crater edge to crater center. This can be attributed to the diffusion 
of element effect of HCPEB. During HCPEB treatment, elements migrated from high concentration areas to low concentration areas under the driving force of chemical gradients. Eventually, element distributions on the alloy surface were uniform. A cyclic process of super-fast heating and cooling promoted element diffusions during HCPEB treatment [31,32].
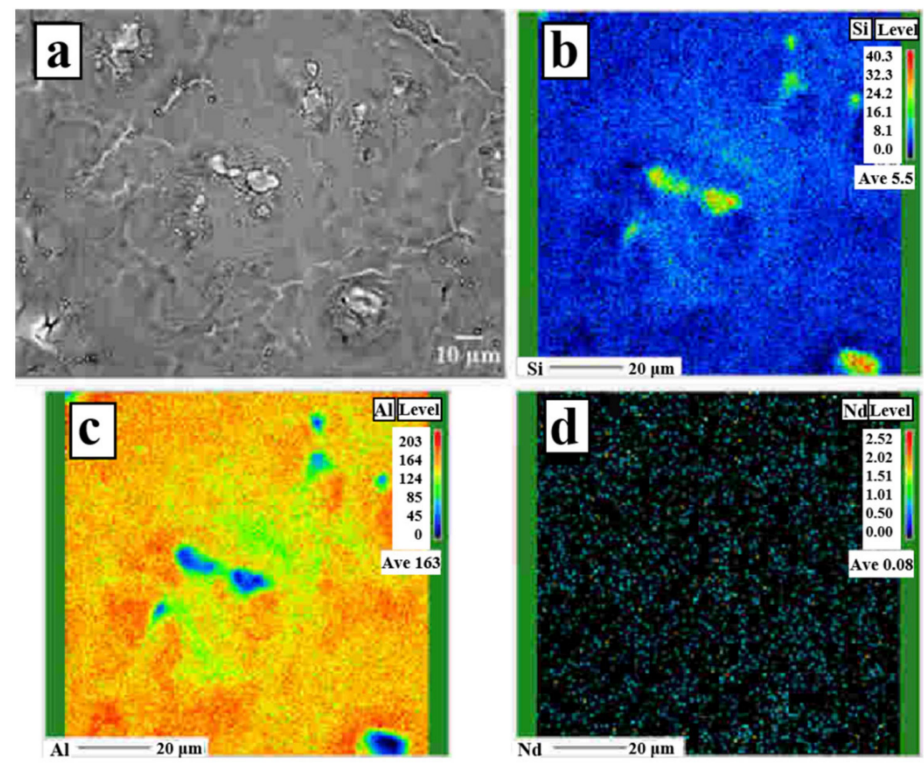

Figure 4. The electron probe micro analyzer (EPMA) image and element distribution graphics of crater structure for HCPEB-processed surface of Al-17.5Si-0.3Nd metallic materials (25 pulses). (a) BSE (backscattered electron) image of EPMA; (b) distribution diagram of $\mathrm{Al}$; (c) distribution diagram of $\mathrm{Si}$; (d) distribution diagram of $\mathrm{Nd}$.

\subsection{TEM Analysis of the HCPEB-Processed Al-17.5Si-0.3Nd Metallic Materials}

Figure 5 shows the TEM results of Al-17.5Si and HCPEB-processed Al-17.5Si-0.3Nd metallic materials (25 pulses). As shown in Figure 5a,c, 100-200 nm nanoscale primary silicon phases were dispersed on the alloy's surface. This can be attributed to the fact that the refinement by Nd addition only occurred in primary silicon phases due to rapid cooling. After HCPEB treatment, $\mathrm{Nd}$ is dissolved in the $\mathrm{Al}$ matrix and $\mathrm{Nd}$ addition had little effect on the size of the nano-silicon generated after the surface modification. Meanwhile, Figure $5 b$,d reveal a typical polycrystalline diffraction ring of $\mathrm{Si}$ phase, according to the SAED (Selected Area Electron Diffraction) pattern. Hence, it can be concluded that nanoscale silicon phases were formed on the top layer of HCPEB-processed alloy. Previous studies [33] reported that the formation of nanoscale silicon phases can be annotated to rapid melting and solidification of alloy surface after HCPEB treatment. At melting state, the silicon atoms migrated to and accumulated on crystal nucleus of silicon. Then, a large number of silicon crystal nuclei grew into silicon crystal grains. Meanwhile, some silicon crystal grains solidified rapidly before growing up due to rapid cooling of HCPEB. Additionally, crystal nucleus grew randomly, (with random crystallographic orientations) and silicon crystal grains may have various orientations [34]. This was demonstrated by the polycrystalline diffraction ring in Figure $5 b$,d. 

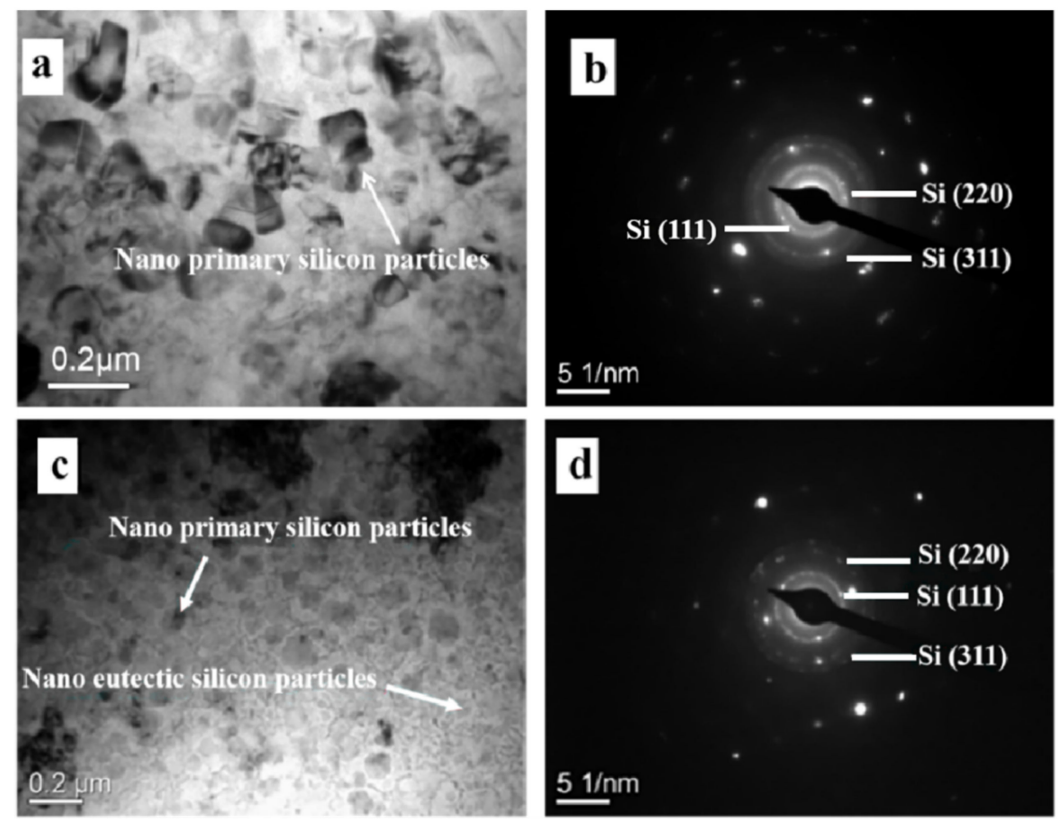

Figure 5. (a) TEM bright-field graphic of HCPEB-treated Al-17.5Si; (b) SAED pattern of HCPEB-treated Al-17.5Si; (c) TEM bright-field graphic of HCPEB-treated Al-17.5Si-0.3Nd; (d) SAED pattern of HCPEB-treated Al-17.5Si-0.3Nd.

Figure 6 displays the TEM results of the nanoscale Al cellular structures and silicon nanoparticles on the HCPEB-processed Al-17.5Si-0.3Nd metallic materials (25 pulses). As shown in Figure 6a, 100 200 nm nanoscale Al cellular structures were uniformly distributed in $\mathrm{Al}$ matrix (Al-rich zone). Meanwhile, $5 \sim 20 \mathrm{~nm}$ silicon nanoparticles precipitated at the crystal boundary or subboundary of Al. Figure $6 \mathrm{~b}$ reveals two sets of diffraction patterns, according to the SAED pattern. First, the single crystal diffraction point of $\mathrm{Al}$ was generated, the orientation difference between $\mathrm{Al}$ grains was small, and the interfaces between grains were small-angle ones, demonstrating that Al cellular structures were sub-grain ones. Second, the nano-silicon polycrystalline diffraction ring was generated, the orientation difference between nano-poly-silicon grains was large, and the interfaces between grains were high-angle ones. Additionally, considerable fine nano-silicon grains precipitated at grain boundaries and sub-grain boundaries of Al cellular structures. The formations of these two structures were related to sharp heating and cooling in the process of HCPEB radiation, just as in the case of nanoscale primary silicon phase $[35,36]$.
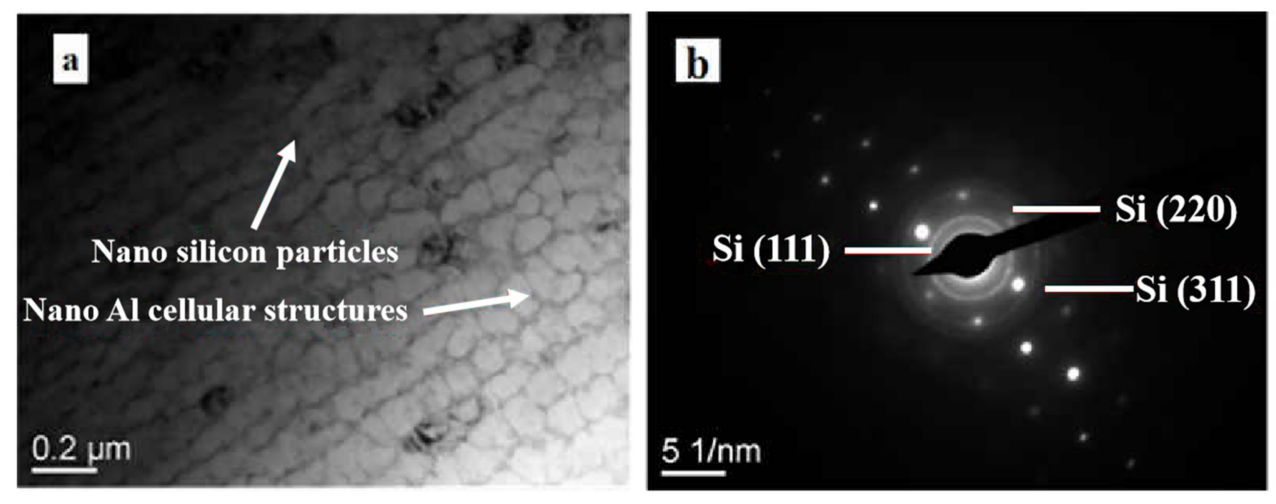

Figure 6. (a) Bright-field image from TEM and (b) corresponding SAED pattern of the HCPEB-processed Al-17.5Si-0.3Nd metallic materials surface ( 25 pulses). 


\subsection{Electrochemical Test}

Electrochemical measurements were involved to investigate the corrosion behavior of fresh and HCPEB-processed hypereutectic Al-17.5Si metallic materials with and without Nd. Figure 7 exhibits polarization curves of the original and HCPEB-processed metallic material surfaces. The electrochemical results obtained from the polarization curves are summarized in Table 1. As observed, the corrosion current density of HCPEB-processed Al-17.5Si metallic material surfaces (25 pulses, $\left.5.175 \times 10^{-5} \mu \mathrm{A} \cdot \mathrm{cm}^{-2}\right)$ was slightly higher than that of initial sample $\left(1.712 \times 10^{-5} \mu \mathrm{A} \cdot \mathrm{cm}^{-2}\right)$. The reduction in corrosion resistance was related to the development of craters and microcracks on the HCPEB-processed Al-17.5Si metallic materials surfaces. These defects can easily induce pitting and stress corrosion on the surface of HCPEB-processed alloy. However, the corrosion current density of HCPEB-treated Al-17.5Si-0.3Nd metallic materials (25 pulses) was $1.021 \times 10^{-8} \mu \mathrm{A} \cdot \mathrm{cm}^{-2}$, which was three orders of magnitude lower than that of HCPEB-treated Al-17.5Si alloy $\left(1.545 \times 10^{-5} \mu \mathrm{A} \cdot \mathrm{cm}^{-2}\right)$ at the same pulse numbers. The amelioration of corrosion behavior can be annotated to grain refinement and elimination of craters [37]. The results suggest that the addition of $\mathrm{Nd}$ is an effective way to eliminate craters and ameliorate the corrosion resistance of aluminum-silicon metal. It helps to expand the application of Al-Si metal in constructions of marine engineering facilities, manufacturing of engine pistons and other corrosion-resistant fields.

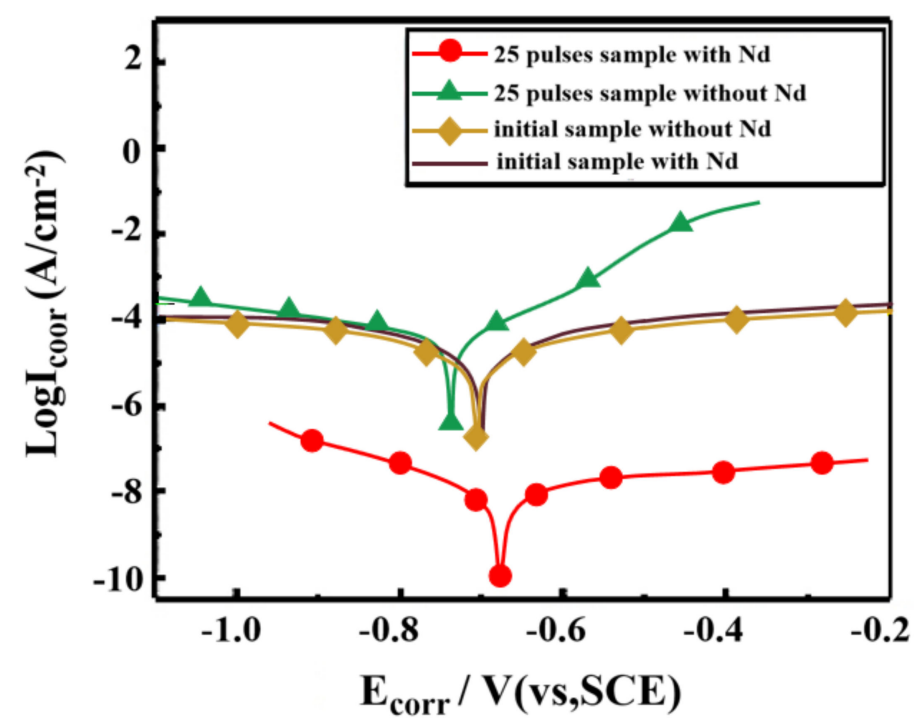

Figure 7. Polarization curves of the Al-17.5Si original sample and HCPEB-processed sample.

Table 1. Electrochemical corrosion measurement test results.

\begin{tabular}{cccc}
\hline Alloy Samples & Number of Pulses & $\mathbf{E}_{\text {corr }}(\mathbf{V})$ & $\mathbf{I}_{\text {corr }}\left(\boldsymbol{\mu A} \cdot \mathbf{c m}^{-2}\right)$ \\
\hline \multirow{2}{*}{ Al-17.5Si } & 0 & -0.7125 & $1.712 \times 10^{-5}$ \\
& 25 & -0.7437 & $5.175 \times 10^{-5}$ \\
\hline \multirow{2}{*}{ Al-17.5Si-0.3Nd } & 0 & -0.7070 & $1.545 \times 10^{-5}$ \\
& 25 & -0.6837 & $1.021 \times 10^{-8}$ \\
\hline
\end{tabular}

\section{Conclusions}

(1) The grains of Al-17.5Si metallic material are refined and craters are removed from the HCPEB-processed Al-17.5Si metallic material surfaces after addition of $\mathrm{Nd}$, according to the SEM analysis. The refinement of the primary silicon can effectively transfer a large amount of heat accumulated in rich-silicon areas, which can effectively inhibit the eruption of primary silicon and eliminate crater structures. 
(2) The XRD analysis indicates that all diffraction peaks are broadened, which can be put down to the presence of structural defects, grain refining and stress state. The TEM analysis indicates that nanoscale Al cellular structures and nanoscale silicon phases are generated on the HCPEB-treated metallic material surface. The generation of these structures can be put down to super sharp cooling and heating effects caused by HCPEB treatment.

(3) EPMA analysis showed that Si and Al are uniformly distributed on the top layer of alloy, which can be attributed to the diffusion of the element.

(4) The corrosion resistance of alloy surface with $\mathrm{Nd}$ is dramatically promoted, and electrochemical measurement exhibits that the corrosion current density of Al-17.5Si-0.3Nd top layer decreases by three orders of magnitude compared with that of Al-17.5Si metallic materials surface. The improvement of corrosion resistance on the top layer of the alloy can be annotated to grain refining and elimination of crater structures.

Author Contributions: Conceptualization, K.L. and B.G.; methodology, K.L.; software, K.L.; validation, K.L., N.X., and V.V.D.; formal analysis, K.L. and N.X.; investigation, K.L. and Y.S.; resources, B.G.; data curation, K.L. and L.H.; writing —original draft preparation, K.L. and B.G.; writing—review and editing, K.L.; visualization, K.L.; supervision, B.G.; project administration, B.G.; funding acquisition, B.G. All authors have read and agreed to the published version of the manuscript.

Funding: This research was funded by the National Natural Science Foundation of China (51671052); the Fundamental Research Funds for the Central University (N182502042); the LiaoNing Revitalization Talents Program (XLYC1902105).

Conflicts of Interest: The authors declare no conflict of interest.

\section{References}

1. Tian, X.S.; Deng, M.J.; Yu, H.; Gao, S.Q. Low Pressure Casting Numerical Simulation of Car Wheel Hub With Al-Si Alloy. Hot Work. Technol. 2016, 15, 345-350.

2. Bösch, D.; Pogatscher, S.; Hummel, M.; Fragner, W.; Uggowitzer, P.J.; Göken, M.; Höppel, H.W. Secondary Al-Si-Mg high-pressure die casting alloys with enhanced ductility. Metall. Mater. Trans. A 2015, 46, 1035-1045. [CrossRef]

3. Liu, X.F.; Wu, Y.Y.; Bian, X.F. The nucleation sites of primary Si in Al-Si alloys after addition of boron and phosphorus. J. Alloy. Compd. 2005, 392, 90-94. [CrossRef]

4. Zhang, H.H.; Duan, H.L.; Shao, G.J. Modification mechanism of cerium on the Al-18Si alloy. Rare Met. 2006, 25, 11-15. [CrossRef]

5. Liu, Y.R.; Zhang, K.M.; Zou, J.X.; Liu, D.K.; Zhang, T.C. Effect of the high current pulsed electron beam treatment on the surface microstructure and corrosion resistance of a Mg-4Sm alloy. J. Alloy. Compd. 2018, 741, 65-75. [CrossRef]

6. $\quad$ Huang, W.X.; Tian, Y.L.; Wang, J.Y.; Sun, Y.L.; Wang, Y.S.; Wang, Y.; Zhao, J.M.; Wu, W.; Ma, L.Z.; He, Y.; et al. Status of Lanzhou Penning Trap for accurate mass measurements. Nucl. Instrum. Methods Phys. Res. Sect. B Beam Interact. Mater. At. 2013, 317, 528-531. [CrossRef]

7. Zhang, C.; Gao, Q.; Lv, P.; Cai, J.; Peng, C.T.; Jin, Y.; Guan, Q. Surface modification of Cu-W powder metallurgical alloy induced by high-current pulsed electron beam. Powder Technol. 2017, 325, 340-346. [CrossRef]

8. Gao, B.; Hu, L.; Li, S.W.; Hao, Y.; Zhang, Y.D.; Tu, G.F.; Grosdidier, T. Study on the nanostructure formation mechanism of hypereutectic Al-17.5Si alloy induced by high current pulsed electron beam. Appl. Surf. Sci 2015, 346, 147-157. [CrossRef]

9. Zhang, X.D.; Hao, S.Z.; Li, X.N.; Dong, C.; Grosdidier, T. Surface modification of pure titanium by pulsed electron beam. Appl. Surf. Sci. 2011, 257, 5899-5902. [CrossRef]

10. Rotshtein, V.P.; Proskurovsky, D.I.; Ozur, G.E.; Ivanov, Y.F.; Markov, A.B. Surface modification and alloying of metallic materials with low-energy high-current electron beams. Surf. Coat. Technol. 2004, 180, 377-381. [CrossRef]

11. Gao, B.; Xu, N.; Xing, P. Shock wave induced nanocrystallization during the high current pulsed electron beam process and its effect on mechanical properties. Mater. Lett. 2019, 237, 180-184. [CrossRef] 
12. Meisner, S.N.; Vlasov, I.V.; Yakovlev, E.V. Impact of electron beam surface modification on deformation behavior and fracture properties of TiNi shape memory alloy. Mat. Sci. Eng. A Struct. 2019, 740, 381-389. [CrossRef]

13. Shulov, V.A.; Nochovnaia, N.A.; Remner, G.E. The effect of crater creation on the fatigue strength and corrosion resistance of steels and titanium alloys irradiated by high-power pulsed ion beams. Surf. Coat. Technol. 2002, 158, 488-493. [CrossRef]

14. Shulov, V.A.; Nochovnaya, N.A. Crater formation on the surface of metals and alloys during high power ion beam processing. Nucl. Instrum. Methods. Phys. Res. 1999, 148, 154-158. [CrossRef]

15. Proskurovsky, D.I.; Rotshtein, V.P.; Ozur, G.E.; Ivanov, Y.F.; Markov, A.B. Physical foundations for surface treatment of materials with low energy, high current electron beams. Surf. Coat. Technol. 2000, 125, 49-56. [CrossRef]

16. Pogrebnjak, A.D.; Mikhaliov, A.D.; Pogrebnjak, N.A.; Tsvintarnaya, Y.V.; Lavrentiev, V.I.; Iljashenko, M.; Valyaev, A.N.; Bratushka, S.; Zecca, A.; Sandrik, R. Evolution of vacancy defects and dislocations in surface layers of iron as a result of pulsed electron beam treatment. Phys. Lett. A 1998, 241, 357-363. [CrossRef]

17. Grosdidier, T.; Zhang, X.D.; Wu, J.; Allain-Bonasso, N.; Zhang, K.M.; Zou, J.X.; Qin, Y.; Li, X.N.; Hao, S.Z.; Dong, C. Crater Eruption Induced by High Current Pulsed Electron Beam (HCPEB) Treatment. In Materials Science Forum; Trans Tech Publications Ltd.: Stäfa, Switzerland, 2010; Volume 654, pp. 1700-1703.

18. Cai, J.; Guan, Q.; Lv, P.; Zhang, C.; Yin, Y. Crater Formation on the Surface of Pure Metal and Alloy Irradiated by High Current Pulsed Electron Beam. High Temp. Mater. Process. 2018, 37, 777-784. [CrossRef]

19. Zhou, Z.M.; Chai, L.J.; Xiao, Z.P.; Jian, T.U.; Wang, Y.P.; Huang, W.J. Surface modification of Cu-25Cr alloyinduced by high current pulsed electron beam. Trans. Nonferrous Met. Soc. China 2015, 25, 1935-1943. [CrossRef]

20. Cai, J.; Guan, Q.; Yang, S.; Yang, S.; Wang, Z.; Han, Z. Microstructural chracterzation of modified YSZ thermal baier coatings by high-current pulsed electron beam. Surf. Coat. Technol. 2014, 254, 187-194. [CrossRef]

21. Zhu, X.P.; Lei, M.K.; Dong, Z.H.; Miao, S.M.; Ma, T.C. Crater formation on the surface of titanium irradiated by a high-intensity pulsed ion beam. Surf. Coat. Technol. 2003, 173, 105-110. [CrossRef]

22. Ferdian, D.; Irawan, K.S.; Lacaze, J. Effect of Cooling Rate and Neodymium Addition on Beta Intermetallic Phase of Al-Fe-Si Ternary System. Trans. Indian Inst. Met. 2018, 71, 2671-2676. [CrossRef]

23. Hu, L.; Gao, B.; Zhu, G.; Hao, Y.; Sun, S.; Tu, G. The effect of neodymium on the microcracks generated on the Al-17.5Si alloy surface treated by high current pulsed electron beam. Appl. Surf. Sci. 2016, 364, 490-497. [CrossRef]

24. Kharina, G.V.; Kochergin, V.P. Corrosion of alloys of aluminum with zinc and rare earth metals in sodium metavanadate solutions. Prot. Metal. 1996, 32, 134-136.

25. Shi, W.X.; Gao, B.; Tu, G.F.; Li, S.W.; Hao, Y.; Yu, F.X. Effect of neodymium on primary silicon and mechanical properties of hypereutectic Al-15\%Si alloy. J. Rare Earths 2010, 28, 367-370. [CrossRef]

26. Shi, W.X.; Gao, B.; Tu, G.F.; Li, S.W. Effect of Nd on microstructure and wear resistance of hypereutectic Al-20\%Si alloy. J. Alloy. Comp. 2010, 508, 480-485. [CrossRef]

27. Ding, W.; Zhao, X.; Chen, T.; Haixia, Z.; Liu, X.; Cheng, Y.; Lei, D. Effect of rare earth Y and Al-Ti-B master alloy on the microstructure and mechanical properties of 6063 aluminum alloy. J. Alloy. Comp. 2020, 830, 154685. [CrossRef]

28. Zhao, Y.; Fan, S.; Zhang, L.; Ma, Z. Absorptivity and Effect of Rare Earth on Pure Copper and Its Alloys. J. Rare Earths 2004, 22, 157-159.

29. Gao, B.; Hao, S.; Zou, J.; Wu, W.; Tu, G.; Dong, C. Effect of high current pulsed electron beam treatment on surface microstructure and wear and corrosion resistance of an AZ91HP magnesium alloy. Surf. Coat. Technol. 2007, 201, 6297-6303. [CrossRef]

30. Gao, B.; Li, K.; Xing, P.F. Formation of a Double-Layer Ultrafine Crystal Structure for High-Current Pulsed Electron Beam-Treated Al-20Si-5Mg Alloy. Coatings 2019, 9, 413. [CrossRef]

31. Gao, Y.K. Surface modification of TC4 titanium alloy by high current pulsed electron beam (HCPEB) with different pulsed energy densities. J. Alloy. Comp. 2013, 572, 180-185. [CrossRef]

32. Hao, S.; Zhao, L.; Zhang, Y.; Wang, H. Improving corrosion and wear resistance of FV520B steel by high current pulsed electron beam surface treatment. Nucl. Instrum. Methods Phys. Res. Sect. B Beam Interact. Mater. At. 2015, 356, 12-16. [CrossRef] 
33. Hu, L.; Gao, B.; Lv, J.K.; Sun, S.C.; Hao, Y.; Tu, G.F. Halo Evolution of Hypereutectic Al-17.5Si Alloy Treated with High-Current Pulsed Electron Beam. J. Nanomater. 2015, 2015, 806151. [CrossRef]

34. Zhang, Q.Y.; Dong, C.; Zou, G.T.; Guan, Q.F.; Chen, B. Stacking fault tetrahedra in single-crystal aluminum induced by high-current pulsed electron beam. Acta Phys. Sin. 2008, 57, 392-397. [CrossRef]

35. Cai, J.; Ji, L.; Yang, S.; Wang, X.; Li, Y.; Hou, X.; Guan, Q. Deformation mechanism and microstructures on polycrystalline aluminum induced by high-current pulsed electron beam. Chin. Sci. Bull. 2013, 58, 2507-2511. [CrossRef]

36. Zou, J.; Grosdidier, T.; Zhang, K.; Dong, C. Mechanisms of nanostructure and metastable phase formations in the surface melted layers of a HCPEB-treated D2 steel. Acta Mater. 2006, 54, 5409-5419. [CrossRef]

37. Zhang, K.; Zou, J.; Grosdidier, T.; Dong, C.; Yang, D. Improved pitting corrosion resistance of AISI 316L stainless steel treated by HCPEB. Surf. Coat. Technol. 2006, 201, 1393-1400. [CrossRef]

(C) 2020 by the authors. Licensee MDPI, Basel, Switzerland. This article is an open access article distributed under the terms and conditions of the Creative Commons Attribution (CC BY) license (http://creativecommons.org/licenses/by/4.0/). 